\title{
A noun scale semantic differential
}

WILLIAM BOGARTZ, UNIVERSITY OF ILLINOIS AT CHICAGO CIRCLE

BERTRAM SIPPOLA, LOUISIANA STATE UNIVERSITY IN NEW ORLEANS

Twenty concepts chosen randomly from the Semantic Atlas were rated by 31 undergraduate $S$ s on a semantic differential consisting of 40 scales defined by concrete high-frequency nouns. Principal component analysis produced a "semantic space" apparently based on associative or category clustering among the scale nouns.

The semantic differential technique (Osgood, Suci, \& Tannenbaum, 1957) purports to measure meaning by factor analysis of the ratings of concepts on a set of bipolar adjective scales, and yields a stable (e.g., Norman, 1959) three dimensional semantic space consisting of evaluative, activity, and potency components. It may be argued, however, that it is almost a priori impossible for three dimensions to characterize a concept precisely enough to allow its identification, up to synonymy, from its coordinates. This study was designed to investigate the plausible hypothesis that the excessively low resolution associated with mapping concepts into semantic space is due to the somewhat abstract adjective scales usually employed, and that ratings on a set of scales based on concrete, "ordinary" nouns would conserve more of the information inherent in the concepts, and thereby approximate more closely to a unique characterization of their denotations.

Method

A semantic differential was constructed using 40 high frequency nouns, which had been rated as highly concrete by seven judges, as scale items. Format and procedure followed Osgood et al (1957), except that each noun appeared at one end of its 7-point scale and the other end was left blank, since these scale items are not bipolar in any nontrivial sense. Twenty concepts chosen at random from the Semantic Atlas (Jenkins, Russell, \& Suci, 1958) were rated by $31 \mathrm{Ss}$ enrolled in the introductory experimental psychology course at the University of Kansas. Instructions were to rate the concept at the top of the page according to its degree of relatedness with each scale noun. The concepts used were: America, boat, brave, church, dawn, deliberate, fragrant, graceful, joy, kitchen, kittens, piano, politician, pungent, rapid, rugged, stop, tall, time, to rnado.

The 40 by 40 matrix of correlations between scales, over all concepts and Ss, was subjected to a principalcomponents factor analysis, after which the first 10 principal components, which accounted for about twothirds of the total variance, were rotated by Kaiser's normal varimax method.

\section{Results and Discussion}

Loadings of the 40 noun scales on the first 10 principal components, after varimax rotation, are shown in Table 1, along with proportions of total variance accounted for by each factor and $h^{2}$ for each scale. A summary of the scales with appreciable loadings on each of the 10 factors will be given here. Loadings above .5 are indicated by an asterisk.

(1) pan*, plate*, stove*, cup*, bean*, sack*, meal*, porch*, grapes*, bone, knife, wine, duck, fish, wheat; (2) bone, tower*, pole*, brick*, oak*, block*, rope*, stone*, tree, head; (3) meal, mail*, bell*, penny*, wine, tongue, bed; (4) sack, knife, pole, rope, insect*, duck*, worm*, wolf*, fish*, tire, needle; (5) meal, porch, knife (-), oak, hair*, bed*, tree*, head, soil, leather; (6)bone, knife, brick, stone, mail, penny, wolf, soil*, tire*, street*, leather; (7) bean $(-)$, grapes $(-)$, rope, stone, tree $(-)$, wheat* $(-)$; (8) block, street, handkerchief*, button*, needle; (9) bean, meal, grapes*, wine*, soil, leather*, handkerchief; (10) porch, brick, penny, tongue*, wolf, head.

It seems quite clear that the factor structure obtained with noun scales is qualitatively different from the three dimensions usually found in semantic differential studies. The scales which load highly on a given factor appear to constitute associative or category clusters, some of which are of transparent composition. While we hesitate to give arbitrary names to the factors, it is obvious that, for instance, Factor (1) has to do with food, or the kitchen (one of the concepts rated), Factor (2) refers to solidity of structure, Factor (4) to wildlife, and so forth. There is no reason to believe that just these factors would be obtained with other scale items, and in order to determine whether there is a functional limit to the dimensionality of semantic space for a given population of Ss, something like Osgood's (Osgood et al, 1957) "thesaurus study" would have to be undertaken.

In any event, this study has shown that the low resolution of "abstract adjective space" is peculiar to the scales used, and that ratings with respect to concrete nouns, and possibly other items of comparable specificity, are more sensitive to denotative aspects of meaning and generate a semantic space in which concepts are potentially more discriminable. It is reasonable to conjecture that "kitchen," for example, would be more nearly recoverable from "pan," "plate," "stove," "cup," etc., than from "savory," "important," "good," "active," or "angular," which are adjective scales related to "kitchen" in the Semantic Atlas (Jenkins et al, 1958).

References

JENKINS, J. J., RUSSELL, W. A., \& SUCI, G. J. An atlas of semantic profiles for 360 words. Amer. J. Psychol., 1958, 71, 688-699 (complete Atlas, Minneapolis: Dept. of Psychology, University of Minnesota).

NORMAN, W. T. Stability characteristics of the semantic differential. Amer. J. Psychol, 1959, 72, 581-584.

OSGOOD, C. E., SUCI, G. J., \& TANNENBAUM, P. H. The measurement of meaning. Urbana: University of Illinois Press, 1957.

Note

1. This research was conducted while the senior author was on the faculty of the University of Kansas. Facilities of the University of Kansas Computation Center were employed. 
Table 1. Complete Noun-Scale Loadings on First Ten Factors: Varimax Rotation Principle of Components Analysis

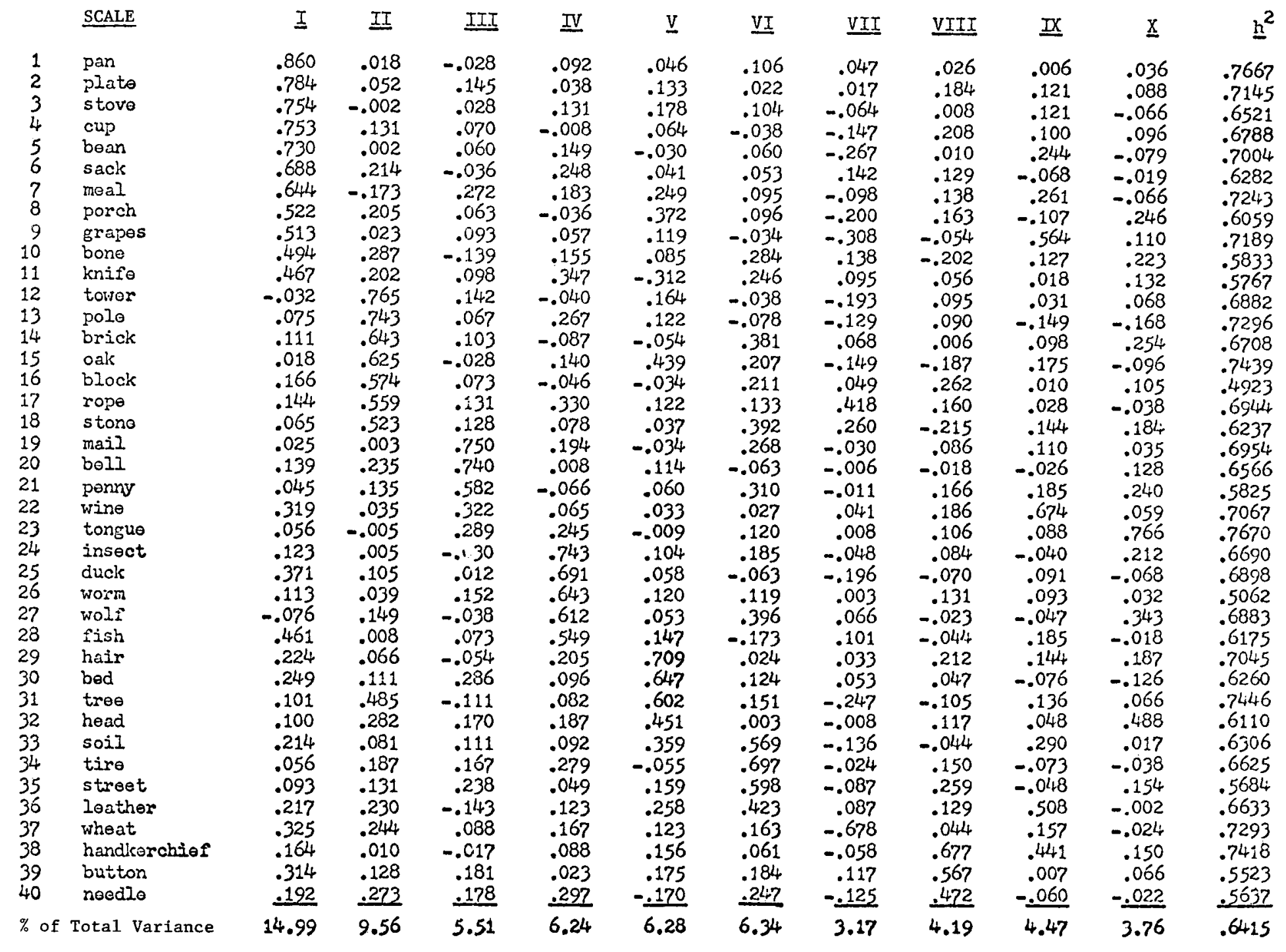

